\title{
SIMULATOR KUBIKEL MINIMUM UNTUK INVESTIGASI GANGGUAN SCADA SISTEM DISTRIBUSI TENAGA LISTRIK $20 \mathrm{KV}$
}

\author{
Wahyu Adi Prasetiyo, Heru Winarno \\ Program Studi Diploma III Teknik Elektro \\ Fakultas Teknik Universitas Diponegoro
}

\begin{abstract}
Wahyu Adi Prasetiyo, Heru Winarno, in this paper explain that with the SCADA system delivery and processing of data from substation equipment consisting of equipment protection, control and measurement becomes faster known by the operator (dispatcher). Measurement and status information indicative of the electric power system are collected in RTU is placed in the substation (GI) which is then sent to the SCADA Master Station.Kinerjasistem dipengaruhiolehpopulasigangguan happened. The more the population of nuisance, then it will significantly reduce the level of reliability of the distribution network which is under the control of the SCADA system. SCADA interference in the distribution of electrical power distribution systems 20 $k V$ affect the level of reliability of the distribution network. Especially if the disturbance of the telecontrol Circuit Breaker. To repair SCADA telecontrol especially the disruption of the necessary investigative trials open close $C B$, but in emergency situations $C B$ load shedding can not be done with the many considerations. Simulator cubicles with Circuit Breaker Dummy serves to replace the function of the actual CB in order to do the test cubicles control of SCADA without load shedding. By removing the SCADA communication in cubicles and then move it to the CB Dummy testing/investigation disorder can be performed optimally. This tool is equipped with IED Digital Meter Relay Protection and SCADA based so that in addition to the investigation failed control can also be used for investigations and telesignal telemetering disorders.
\end{abstract}

Keywords: scada, investigations, reliability.

\section{PENDAHULUAN}

Kubikel 20 KV merupakan seperangkat peralatan listrik yang dipasang pada Gardu Distribusi yang berfungsi sebagai pembagi, pemutus, penghubung pengontrol dan proteksi sistem penyaluran tenaga listrik tegangan $20 \mathrm{KV}$. Untuk menjaga stabilitas dan meningkatkan keandalan dalam pengoperasiannya kubikel tersebut saat ini sudah menerapkan sistem SCADA (Supervisory Control And Data Acquisition).

SCADA berfungsi mulai dari pengambilan data pada Gardu Induk atau Gardu Distribusi, pengolahan informasi yang diterima, sampai reaksi yang ditimbulkan dari hasil pengolahan informasi. Dengan adanya sistem SCADA penyampaian dan pemrosesan data dari peralatan gardu induk yang terdiri dari peralatan proteksi, kontrol dan pengukuranmenjadi lebih cepat diketahui oleh operator (dispatcher).Informasi pengukuran dan status indikasi dari sistem tenaga listrik dikumpulkan di RTU yang ditempatkan di Gardu Induk (GI). Kontrol penyaluran sistem peralatan memungkinkanpenyampaian data secara remote.

Agar peralatan SCADA dapat beroperasi normal, optimal, andal dan memenuhi standar kinerja perlu dilakukan pemeliharaan secara preventif, prediktif maupun korektif. Pelaksanaan pemeliharaan/perbaikan instalasi SCADA tidak terlepas dari kemungkinan adanya pelepasan beban distribusi, sedangkan dalam kondisi pemeliharaan yang sifatnya darurat/korektif kadang tidak dimungkinkan dilakukannya pelepasan beban oleh karena itu diperlukan suatu alat bantu untuk menggantikan fungsi $\mathrm{CB}$ sebenarnya pada saat pemeliharaan.

\section{Perumusan Masalah}

Berdasarkan latar belakang di atas dapat dirumuskan permasalahan yang akan diselesaikan dalam tugas akhir ini adalah

- Bagaimana merancang Simulator Kubikel dilengkapi dengan IED Relai Proteksi dan Meter berbasis SCADA.

- Bagaimana Simulator Kubikel dapat menggantikan fungsi $\mathrm{CB}$ sebenarnya pada kubikel.

\section{Batasan Masalah}

Agar dalam pembahasan ini lebih terarah, penulis membatasi permasalahan yang akan dibahas yaitu :

- Langkah-langkah perancangan dan penyusunan Simulator Kubikel.

- Kerja Relai Elekromekanik 110 VDC sebagai simulator Open/Close Circuit Breaker

- Prinsip kerja iOlogik Moxa RS2110 sebagai Telecontrol SCADA

- Prinsip kerja Meter Digital Gae sebagai Telemetering SCADA

\section{DASAR TEORI \\ Kubikel 20 KV Gardu Induk}

Kubikel ini merupakan seperangkat peralatan listrik yang dipasang pada Gardu Distribusi yang berfungsi sebagai pembagi, 
pemutus, penghubung pengontrol dan proteksi sistem penyaluran tenaga listrik tegangan $20 \mathrm{KV}$. Kubikel pada dasarnya adalah lemari sebagai tempat terpasangnya peralatan kontrol, pengukuran, proteksi, dan announciator, yang dimaksudkan untuk mempermudah operasi dan pemeliharaan serta keamanan bagi operator. (Pusdiklat PLN; 2010).

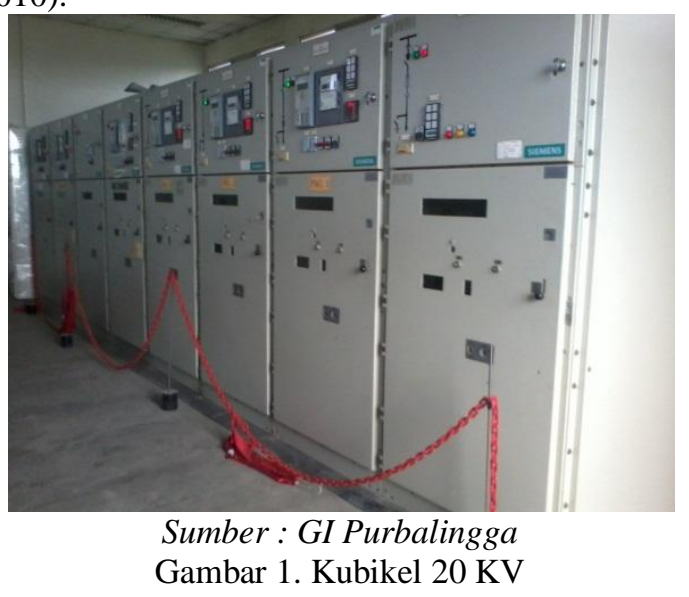

\section{Kubikel CB Outgoing (PMT)}

Berfungsi sebagai pemutus dan penghubung arus listrikdengan cepat dalam keadaan normal maupun gangguan. Kubikel ini disebut juga dengan istilah kubikel PMT (pemutus tenaga) yang dilengkapi degan relai proteksi dan biasanya di pasang sebagai alat pembatas, pengukuran dan pengaman pada pelanggan tegangan menengah. Curent transformer (CT) yang terpasang memiliki double secunder satu sisi untuk mensuplai arus ke alat ukur kwh dan satu sisi lagi untuk menggerakan relai proteksi pada saat terjadi gangguan. (Pusdiklat PLN; 2010).

\section{Over Current Relai}

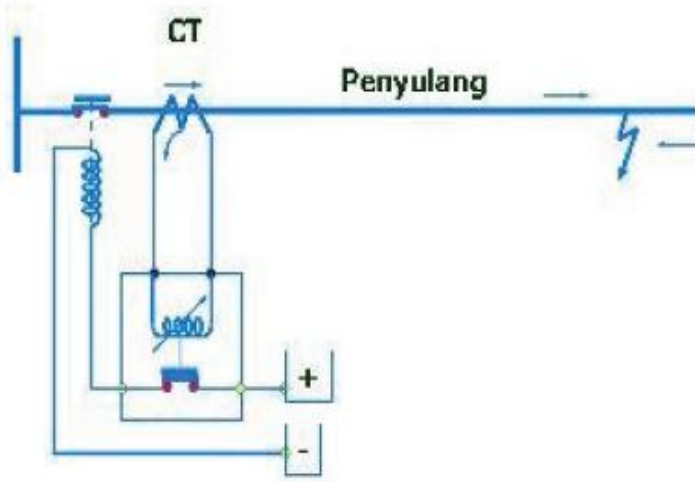

\section{Sumber : budi54n.wordpress.com Gambar 2. Prinsip OCR/GFR}

Relai arus lebih-OCR memproteksi instalasi listrik terhadap gangguan antar fasa. Sedangkan untuk memproteki terhadap gangguan fasa tanah digunakan relai RelaiRelai Arus Gangguan tanah atau Ground Fault RelaiRelai (GFR). Prinsip kerja GFR sama dengan OCR, yang membedakan hanyalah pda fungsi dan elemen sensor arus. OCR biasanya memiliki 2 atau 3 sensor arus (untuk 2 atau 3 fasa) sedangkan GFR hanya memiliki satu sensor arus (satu fasa).

\section{SCADA (Supervisory Control And Data Acquisition)}

SCADA singkatan dari Supervisory Control and Data Acquisition. Dimaksudkan dengan SCADA adalah suatu sistem pengawasan, pengendalian dan pengolahan data secara real time. Real time dalam sebuah sumber disebutkan, "real time"dalam ungkapan yang sederhanadikatakan bahwa, pemakai bertanya kepada sistem komputer lalu sistem komputer mengolah dan menjawabnya. Sistem ini disebut juga sebagai sistem interaktif karena ada dialog antara pemakai dan sistem komputer dan hasilnya tersedia segera." (Heijerdan Tolsma, 1988, h.12)

\section{IED (Intelligent Electronic Device)}

Istilah "Intelligent Electronic Device" adalah perangkat elektronik multifungsi yang memiliki beberapa jenis kecerdasan lokal. Di bidang proteksi dan sistem otomatisasi daya bidang industri, IED merupakan sebuah perangkat yang memiliki fungsi serbaguna diantaranya untuk perlindungan listrik/proteksi, intelegent kontrol, kemampuan monitoring dan kemampuan komunikasi yang luas secara langsung ke sistem SCADA. (http://scadaied.blogspot.com/).

Kemampuan IED untuk melakukan semua fungsi perlindungan, pengendalian, pemantauan, dan komunikasi tingkat atas secara independen dan tanpa bantuan perangkat lain seperti RTU (Remote Terminal Unit) atau prosesor komunikasi (tidak termasuk modul interface) adalah fitur yang dimiliki dari IED.

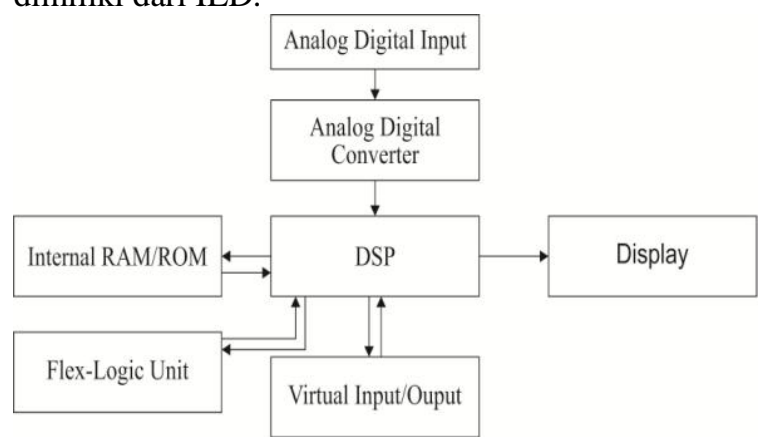

Gambar 1. Konfigurasi IED

\section{Komunikasi RS485}

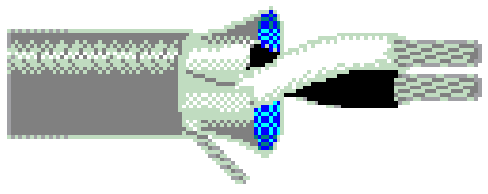

Gambar 2. Cabel RS485 Belden 8760 
RS-485 digunakan dalam sistem otomatisasi sebagai kabel bus sederhana dan kabel yang panjang, sangat ideal untuk menghubungkan dengan perangkat remote. RS-485 memungkinkan konfigurasi jaringan lokal dan link komunikasi multidrop. Dalam jarak $10 \mathrm{~m}$ mampu mengalirkan data dengan kecepatan $35 \mathrm{Mbit} / \mathrm{s}$ dan $100 \mathrm{kbit} / \mathrm{s}$ pada jarak $1200 \mathrm{~m}$. Karena menggunakan diferensial garis seimbang selama twisted pair, dapat menjangkau jarak yang relative besar (hingga $1.200 \mathrm{~m}$ ). (http://en.wikipedia.org/).

\section{RencanaPengamatan}

Rencana pengamatan karya implementasi teknologi "Simulator Kubikel Minimum Untuk Investigasi Gangguan SCADA Sistem Distribusi Tenaga Listrik 20 KV" ini adalah dengan memahami konsep prinsip kerja alat dan penggunaanya.

\section{Gambar Blok Diagram}

Blok diagram dari "Simulator Kubikel Minimum Untuk Investigasi Gangguan SCADA Sistem Distribusi Tenaga Listrik 20 KV" ditunjukkan pada Gambar 5.

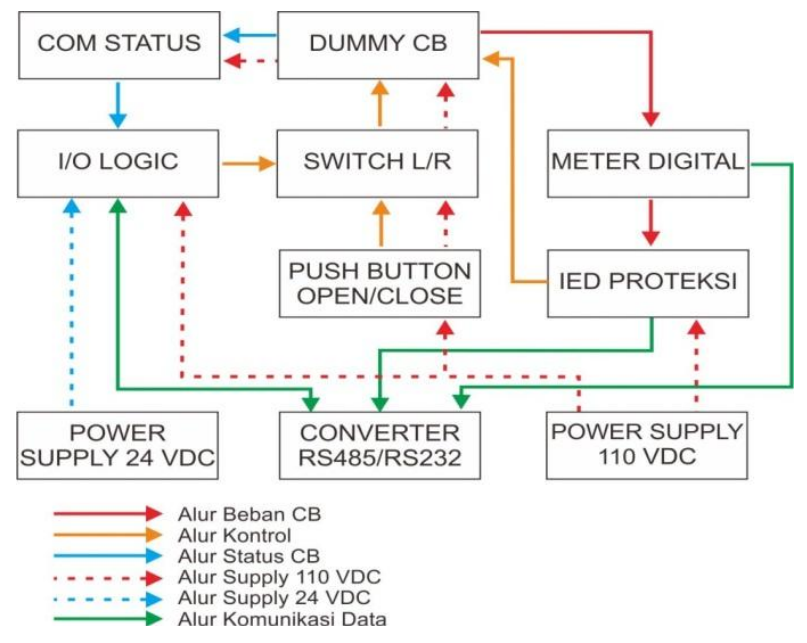

Gambar 3. Blok Simulator Kubikel

\section{CARA PENGAMATAN}

Secara umum garis besar penyusunan laporan dapat digambarkan melalui Diagram Alir (Flowchart) pada Gambar 6.

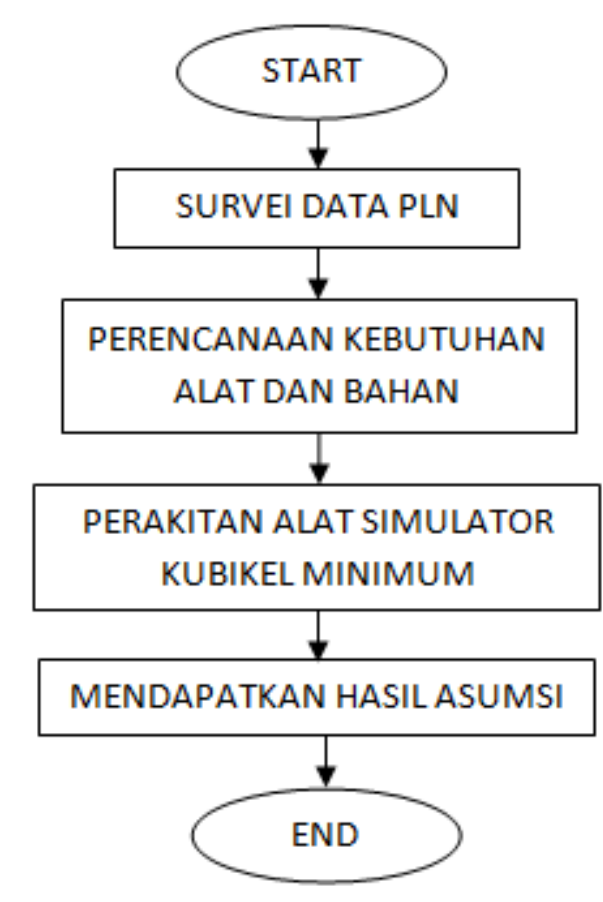

Gambar 6. Diagram AlirPengamatan

\section{HASIL PENGAMATAN DAN PEMBAHASAN} Pengontrolan Simulator Kubikel Minimum

Pengontrolan Simulator kubikel dilakukan dengan dua metode yaitu Local dan Remote berdasarkan posisi Mode Control Switch pada panel Simulator.
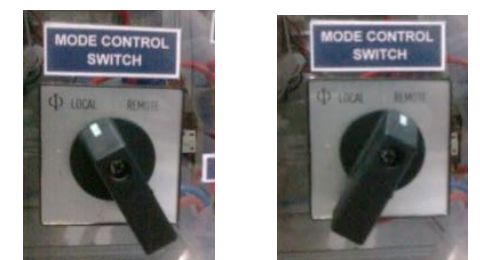

Gambar 7. Mode Control Switch Local (kiri) dan Remote (kanan)

Secara Local dilakukan dengan menekan tombol langsung pada panel Simulator, dengan Remote dilakukan dari HMI SCADA.

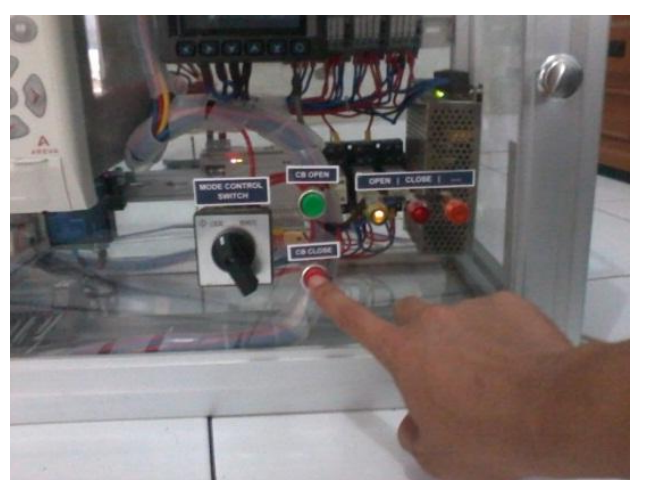

Gambar 8. Kontrol Local Simulator 
Kontrol secara Lokal hanya dapat dilakukan apabila Mode Switch dalam kondisi Local. Saat tombol warna merah ditekan Dummy CB akan berubah menjadi posisi Close, yang akan bekerja menyalurkan arus dari current injector ke meter dan proteksi. Sedangkan saat tombol hijau ditekan Dummy CB akan menjadi posisi Open, arus dari currentinjector ke meter dan proteksi terputus.

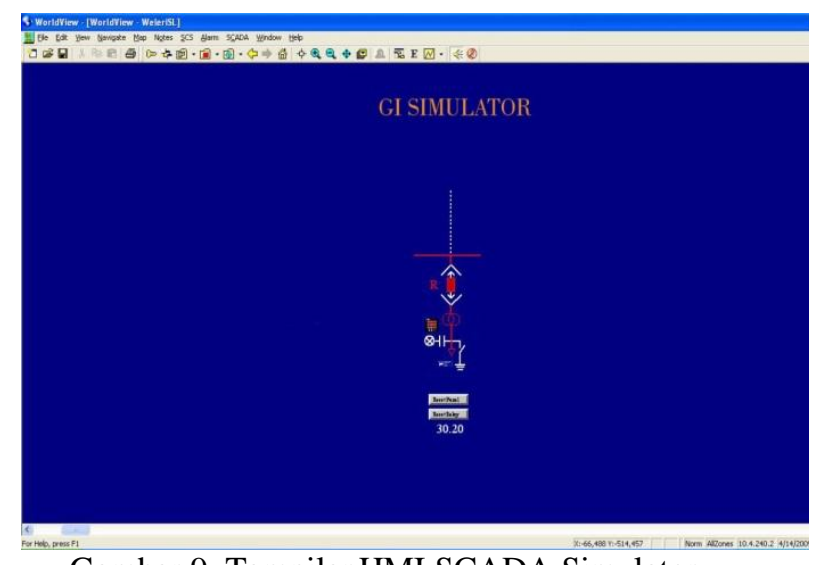

Gambar 9. TampilanHMI SCADA Simulator

Untuk dapat dikontrol secara Remote Mode Switch juga harus dalam kondisi remote. Dilakukan dengan menekan mengklik logo CB pada tampilan HMI. Untuk perintah Open $C B$ langkah yang harus dilakukan :

- Memastikan status posisi CB $\boldsymbol{v}$ (closed) dan CB dalam keadaan $\mathbb{V}$ (remote)

- Klik gambar $\mathbb{v}$ pada CB yang ingin di open hingga tampil kotak dialog.

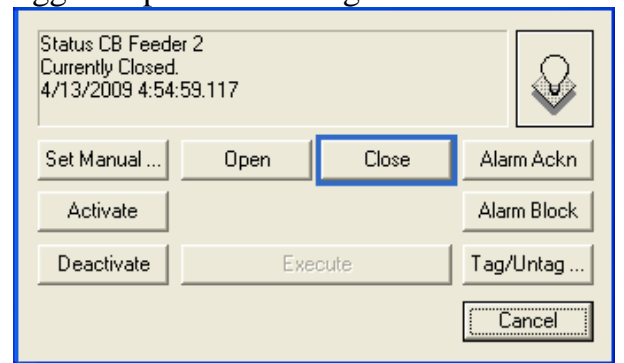

Gambar 10. Kotak dialog Control CB

- Klik Open $\rightarrow$ Execute

- Setelah CB berhasil di open, simbol penyulang akan berkedip dan berubah warna dari $\downarrow$ menjadi $v$.
Dan untuk PerintahClose $\mathrm{CB}$, langkah yang harus dilakukan :

- Memastikan status posisi CB open $\mathbb{\Downarrow}$ dan posisi $\mathrm{CB}$ dalam remote.

- Klik gambar $\mathbb{v}$ pada CB yang ingin di close. Hingga tampil kotak dialog.

- Klik Close $\rightarrow$ Execute

- Setelah CB berhasil di close, alarm akan berbunyi, simbol penyulang akan berkedip dan berubah warna dari $\mathbb{v}$ menjadi

Penandaan Indikator Status pada Panel dan Peralatan Simulator

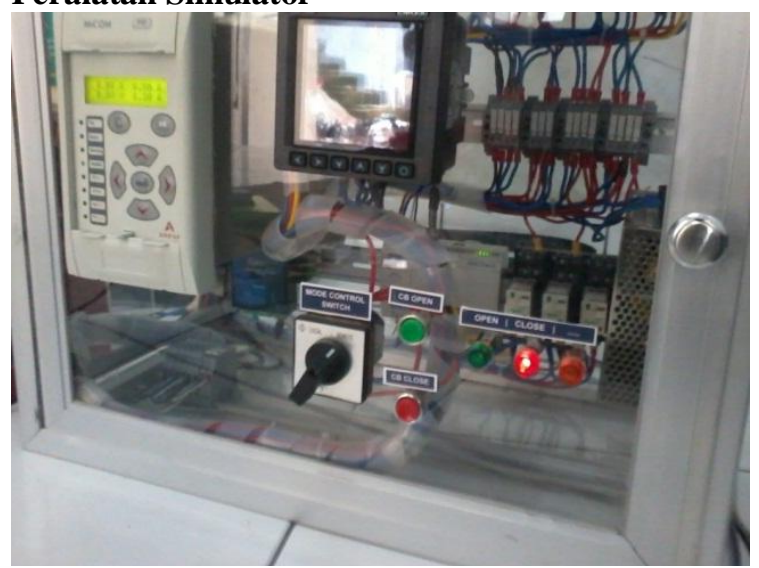

Gambar 11. Panel Simulator

Indikator LED merah menyala dan hijau mati, ini menandakan bahwa Dummy $C B$ dalam keadaan Close dan dapat bekerja menyalurkan arus dari current injector ke meter dan proteksi. Apabila LED hijau menyala dan merah mati, Dummy $C B$ dalam keadaan Open (kontak membuka) menandakan bahwa arus dari current injector tidak dapan mengalir ke meter dan proteksi.

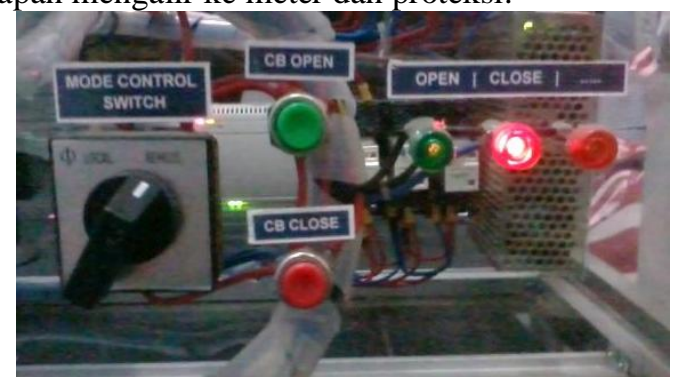

Gambar 12. CB dalam Posisi Close 


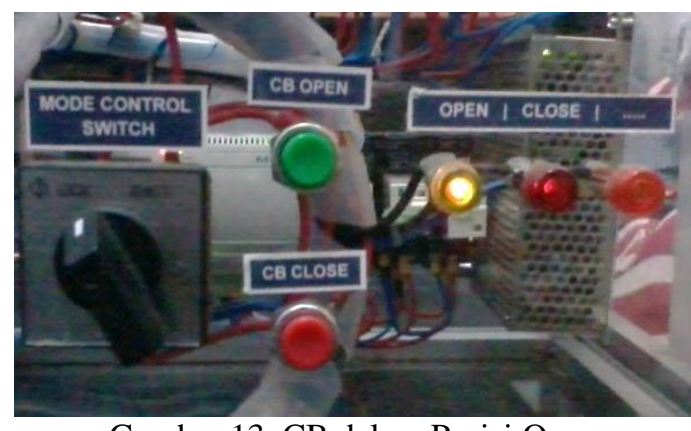

Gambar 13. CB dalam Posisi Open

Selain pada panel Simulator status CB juga ditampilkan di LED indikator perangkat IO Logic. Apabila LED DI0 menyala menandakan CB dalam kondisi Close, LED DI1 menandakan CB dalam kondisi Open dan LED DI2 menandakan bahwa simulator dalam kondisi remote.

\section{Penandaan Indikator Status pada HMI Simulator}

Status Penyulang berwarna merah, ini menandakan bahwa Dummy $C B$ dalam keadaan Close dan dapat bekerja menyalurkan arus dari current injector ke meter dan proteksi. Apabila Penyulang berwarna hijau, Dummy $C B$ dalam keadaan Open (kontak membuka) menandakan bahwa arus dari current injector tidak dapan mengalir ke meter dan proteksi. Penentuan warna merah atau hijau berdasarkan SPLN Standar Gambar HMI yang menjelaskan bahwa indikasi merah $\square$ menandakan close, sedangkan hijauL menandakan open pada device/jaringan.

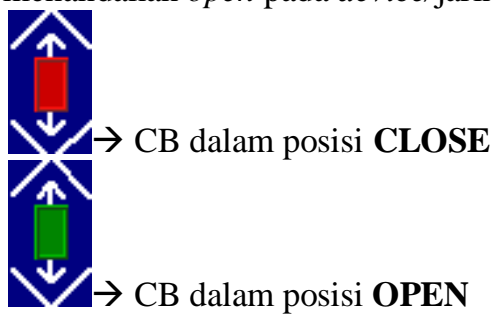

Status Dummy $C B$ terdapat huruf R dibagian samping kiri menandakan bahwa $C B$ dalam keadaan Remote. Apabila Dummy $C B$ terdapat huruf $L$ dibagian samping kiri menandakan bahwa $C B$ dalam keadaan Local.

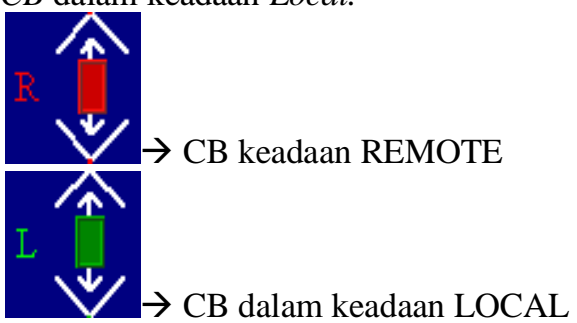

Status Dummy $C B$ terdapat huruf F dibagian samping kiri bawah menandakan bahwa komunikasi Simulator dan master tidak berkomunikasi (failure). Apabila tidak ada huruf $\mathrm{F}$ menandakan komunikasi Simulator dalam keadaan

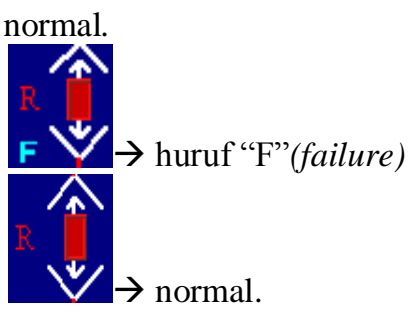

Status gangguan yang terjadi di relai proteksi ditampilkan pada samping kanan simbol penyulang pada HMI. Apabila terdapat huruf A maka gangguan yang terjadi pada fasa $A$ atau $R$ penyulang, apabila terdapat huruf $\mathrm{B}$ maka ganggaun yang terjadi pada fasa $B$ atau $S$ penyulang, dan apabila terdapat huruf $\mathrm{C}$ maka gangguan yang terjadi pada fasa $\mathrm{C}$ atau $\mathrm{T}$ penyulang, sedangkan indikasi waktu kerja relai akan ditampilkan pada sebelah kiri bawah simbol penyulang, INS menandakan waktu kerja relai instant sedangkan jika waktu delay tidak ditampilakan.

$\begin{array}{lr}\rightarrow & \text { relai } \\ \text { gangguan } \\ \text { dengan waktu }\end{array}$

\section{KESIMPULAN}

Dari pengamatan karya implementasi teknologi yang membahas mengenai SIMULATOR KUBIKEL MINIMUM UNTUK INVESTIGASI GANGGUAN SCADA SISTEM DISTRIBUSI TENAGA LISTRIK $20 \mathrm{kV}$ " penulis mendapatkan beberapa kesimpulan:

- Simulator kubikel tersusun oleh relai elekromekanik 110 Vdc sebagai Dummy Circuit Breaker tersusun dari 2 buah relai dengan sistem interlock, yang akan bekerja saat mendapat input trigger tegangan pada salah satu coilnya.

- Alat ini sudah berhasil dibuat dan sampai saat ini berfungsi dengan baik sebagai alat investigasi gangguan SCADA sistem distribusi tenaga listrik $20 \mathrm{kVdi}$ PT PLN APD Jatengdan DIY.

- Dengan adanya simulator kubikel diharapkan dapat membantu menganalisa penyebab gangguan SCADA, karena dengan alat ini ketikadiharuskan untuk penanganan di site, petugas tidak perlu melakukan pelepasan beban distribusi untuk tes kontrol CB. Hal ini dapat membantu mempercepat pemulihan gangguan agar waktu gangguan tidak terlalu lama.

\section{DAFTAR PUSTAKA}

1. Alstom. 2010. Technical Guide MiCOM P120/P121/P122 \&P123 .http://www.electricalmanuals.net/files/RELA 
YS/../P12x-EN-T-E65.pdf.Diunduh tanggal 12 April 2013 pukul 16.20 WIB.

2. Anonim. 2012. IED (Intelligent Electronic Device) used in Supervisory Control and Data Aquisition System. http://scadaied.blogspot.com/2012/07/ied-intelligentelectronic-device-used.html.Diunduh 2 Juni 2013 pukul 15.21 WIB.

3. Dokumentasi Standar SCADATEL. Pola Scada. http://scada.pln-jawabali.co.id/Pola\%20SCADA/.Diunduhtanggal 12 April 2013 pukul 16.25 WIB.

4. Gustyanto, Tito. 2012. Penerapan Sistem SCADA Pada Penegndalian Jaringan Tegangan Menengah $20 \mathrm{kV}$ Di PT.PLN (Persero). Depok : UniversitasGunadarma.

5. Heijer, P.C. den; \& Tolsma, R. 1988. Komunikasi Data. Lily Wibisono (Penerjemah). Jakarta: PT Elex Media Komputindo kelompok Gramedia.

6. Moxa. ioLogik E2210 User's Manual. www.moxa.com/support/DownloadFile.aspx?. Diunduh 2 Juni 2013 pukul 19.30 WIB.

7. PT Guna Era Industri. 2012. Instalation and Operation Manual EMG30. Jakarta : PT Guna Era Industri).

8. PT PLN (Persero) APD Jateng DIY. 2011. SCADA PLN Jateng DIY. Tidak diterbitkan.
Semarang : PT PLN (Persero) APD Jateng DIY

9. Puspitaningayu, Pradini. 2011. Digital Signal Processor (DSP). http://prandinipus.wordpress.com//. Diunduh 6 Juni 2013.

10. Rustawan, Dedi. 2012. Pengoperasian PMT Penyulang $20 \mathrm{KV}$ dengan SCADAPT PLN (Persero) Area PengaturDistribusi Semarang. Laporantidakditerbitkan. Semarang : Universitas Semarang.

11. Sofwan, dkk. 2005. Analisis Penyebab Out Of Scanning pada SCADA akibat Gangguan RTU. Yogyakarta : Institut Sains dan Teknologi Nasional.

12. Wicaksono, Handy. 2012. SCADA Software dengan Wonderware InTouch Dasar-dasar Pemograman Edisi Pertama. Yogyakarta: Graha Ilmu.

13. Wikipedia. 2013. Digital protective relay. http://en.wikipedia.org/wiki/Digital_protective _relay. Diunduh 4 Juni 2013 pukul 20.03 WIB.

14. Wikipedia. 2013. Dioda Zener. http://id.wikipedia.org/wiki/Dioda_Zener.Diu nduh 13 Juni 2013 pukul 14.00 WIB. 